\title{
Publishing Patterns of Health Informatics in Africa: A Bibliometric Analysis
}

\author{
Rexwhite Tega Enakrire \\ University of South Africa, Pretoria \\ enakrrt@unisa.ac.za \\ rexwhite.enakrire80@gmail.com
}

\begin{abstract}
This study investigates the publishing patterns of health informatics (HIs) in Africa, with a view to analyse the bibliometric growth. The application of HIs has played an important role in the advancements in medical practice and scholars/academics' teaching and learning at higher education institutions. The aim of analysing the volume of publications of HIs was to establish the research impact, visibility and output of academics, in order to promote scholarly communication and knowledge sharing, and contribute to existing knowledge in this field of study. Interpretive document analysis was applied to literature extracted from the Scopus database for the period between 1987 to 2018 . The keywords entered for search engine optimisation were "Health Informatics" and "Africa". The duration of the study - from when data was harvested, collated and analysis to when the data was presented in tables and then discussed - was three weeks. The results obtained revealed that there were 2332 papers published within this period. The publications were communicated through different avenues, including articles, conference papers, review and others. Publications on medicine was at the top of the list of subject areas recorded. The top journal, where papers in HIs were published, is Plos One. South Africa was among the top countries that published research on HIs. In relation to institution affiliation, University of Cape Town was identified as the higher education institution that produced the highest number of publications, with 128 publications. In terms of funding bodies that supported research, thus leading to publication of papers in HIs, it was found that the National Institute of Health, South African Medical Council, United States Agency for International Development, Bill and Melinda Gates Foundation, National Institute of Allergy and Infectious Diseases, National Research Foundation played crucial roles.
\end{abstract}

Keywords: Publishing patterns, health informatics, information systems tools, bibliometric analysis, Africa

\section{Introduction and conceptual background of the study}

The primary focus of this study was to investigate the publishing patterns in the field of health informatics (HIs) in Africa, with emphasis on the growth patterns from 1987 to 2018. HIs field become important because it support the principle of accountability for better service delivery in healthcare system. Accountability ensures that healthcare professionals and scholars/academics apply fundamental knowledge and utilise up-to-date technologies when providing health care to ensure quality care and efficient service delivery in the health or medical sector. The field of HIs which is under the umbrella of health or medical practices, requires adequate knowledge and skills of the healthcare officer or medical practitioner. The essence of the knowledge in the healthcare environment is to make good use of the available health data combined with the information about patient. Healthcare professionals and scholars/academics in related fields have substantive and considerate empathy for people with health challenges, even though they are not supposed to. This was in relation to the calling which the profession of the healthcare or medical practices profess, where they go extra miles in fulfilling the obligations of quality service delivery. The healthcare or medical practices ensure this through end user of HIs documents of patients or individual concerned that require assistance or support (Al-Rowibah, 2019). Scholars/academics therefore consult documents in Hls, to assist in their research, as well as teaching and learning activities, in higher education institutions. However, many scholars/academics and healthcare or medical practitioners, who are supposed to be the end users of HIs documents, do not have access to published documents simply because they are accessible to them. This was one of the reasons the author of this paper was driven to investigate the publishing patterns of health informatics (HIs) in Africa, such that scholars/academics and healthcare or medical practitioners would know and have access to where information published and situated in HIs. Another justification that necessitated this study, for this researcher, was the expectation of promoting quality service delivery by healthcare or medical practitioners by exploring the efficacy of aligning health services with the use of technologies to assist in the diagnosis and treatment of different ailments. This is not possible without a vast knowledge of HIs, which can be accessed through application of technologies, as earlier mentioned. It was established that, since there has been a tremendous shift in healthcare or medical practices in recent times, scholars/academics and healthcare or medical practitioners need to be upskilled, in order to be prepared for unprecedented situations that would require their knowledge articulation (Ammenwerth, 2019; Sullivan, 2001). This tremendous shift has brought about the need for scholars/academics 
and medical practitioners to intensify their research skills and knowledge, such that, exploring different dimensions would not be a problem to them (Ammenwerth, 2019; Sullivan, 2001). Aziz (2015) notes that, in the past few decades, there has been an increase in the publication of medical information. This has brought about a tremendous growth in the scope of medical specialities and different sub-disciplines. This was to advance the quality of service delivery in the healthcare profession. In order to harness emerging information or knowledge in healthcare or medical practices, medical practitioners and scholars/academics would need to access this knowledge to strengthen practices and their research, as well as teaching and learning. Thus, advancing track record that would build up to speed with the latest medical knowledge, inclusive of HIs, required to assist medical practitioners and scholars/academics in the execution of their job (Aziz, 2015).

Based on the author's exposition and experiences, certain decisions made by medical practitioners and/ or scholars/academics are determined by the data, information and knowledge at their disposal or they possess. This could have been obtained through published resources in HIs databases. Therefore, to harness the data, information and knowledge in HIs, the need to make available, accessible and use the publications in HIs become essential, hence the interest of the researcher in this study. This study unveils the increase in availability of HIs, in relation to other areas of study, such as human-computer interactions, data mining, healthcare management systems, among others.

The consideration of African continent in this study by the author of this paper, was due to the adequacy of many mineral resources (Mapping Africa's natural resources, 2018). The availability of such vast mineral resources should ensure the creation of a conducive environment for the citizens of Africa equal to that experienced in the developed world such as the USA, Canada, Europe, UK, New Zealand just to mention a few. Unfortunately, one of the best places where development has taken effect, to some extent, is South Africa (the "Europe of Africa"), but in other African countries, development, specifically with regard to infrastructure, is still in its infancy in many parts of the continent. The essence of the effect of the infrastructure was to enhance publication growth of scholars/academics and medical practices required to support citizens in their different areas of specialisations.

The author felt that considering how resourceful or rich, the African continent is, compared to the developed world, their healthcare system has not support service delivery as expected and scholars/academic in terms of publication growth in HIs areas of study. The resources in Africa could be used if adequately harnessed, to expand higher education institutions for better teaching and learning outcomes in medicine, computer technology, information science and knowledge management. Besides, the land in Africa could be developed, in terms of farm agriculture/cultivation, to enhance the living standards of her citizens. The monetary value that should be gained from its mineral resources should cater for the basic needs of citizens in all the fifty-four countries in Africa, including the provision of services, such as education and health care, and infrastructural development through investment in the construction industries and many more activities and development initiatives in these countries. The author of this paper is seeking for answer on why the scenario of the continent is still like this, hence this research investigation. This research paper could serve as an eye opening to other scholars and stakeholders in various organisation and related institutions. This they could do through proper engagement in interaction with scholars and medical practitioners, on writing a proposal or framework that could address issues of support in ongoing research in HIs in Africa. Drawing analogy from the above emphasis, specifically in the area of HIs in Africa, most of the research work published are not easily accessed, since some of them may not have been published in textbooks or entered into online databases. However, HIs might be a resource that is required in higher education, to educate health professionals in different capacities. Besides, some of the journals that publishes HIs in the fifty-four (54) countries in Africa are not online or not recorded on indexed databases. This might also pose a challenge on how Hls publication could be harness and harvested. Although substantive research in HIs across the globe and, specifically, in Africa has been investigated. The documentation regarding such bibliometric analysis has not be done hence this study seeks to ascertain the growth, trends and visibility of research outputs in HIs and the impact this has had in Africa.

HIs, according to different scholars, is a multidisciplinary field of study (Kazemi, n.d.; Al-Rowibah, 2019; Ammenwerth, 2019). It is an interdisciplinary field that has its origin in medicine, computer technology and information science. From this multidisciplinary field, other sub-divisions developed, which include bioinformatics, medical informatics, clinical informatics, nursing informatics, biosciences, healthcare informatics and knowledge management (Kazemi, n.d.; Al-Rowibah, 2019; Ammenwerth, 2019). A study by Ammenwerth (2019) alludes that, HIs is concerned with the application of computers and other related digital technologies, 
to assist in the gathering, processing, storage and use of information, to advance the techniques and procedures utilised in healthcare service delivery. Drawing inference from the Health administration degree program (n.d), it could be established that, HIs is an evolving field, exclusive to the medical profession. It entails different technologies and communication facilities that are required for healthcare services, to ensure optimal outcomes in patient care. The different areas mentioned make use of the resources of data, tools, procedures and strategies for optimum processes of acquisition, storage, retrieval and use of information and data in healthcare service delivery, management and planning. Al-Rowibah (2019) asserts that, HIs has dual understanding: scientific and information science. The former, is concerned with technical integration of reasoning, where information is used to process and communicate healthcare practices based on the training and research carried out through the support of technologies. While the latter, advocates for management operations of health data and information through the application of computers and related technologies (Al-Rowibah, 2019). These are used to advance the delivery of healthcare services, specifically in regard to the diagnosis of diseases and other activities that require research investigations. The tools in question are computer, magnetic and optical lens (AlRowibah, 2019). The data, information and tools used are appropriated in a variety of ways to enhance the method of approach in handling patient issues and research investigations within and outside hospitals and organisations. The author of this study believes that the changing nature of medical practice today, and the complexity of some ailments, requires adequate health knowledge and the application of the most recent technological tools in order to diagnose and cure such ailment, timeously.

An analysis of publications in HIs would be valuable to medical practitioners and researchers/academic scholars in the field of computer science, healthcare and information science, among others, to able to determine the publication trends in these areas. The goal of the study was to have identify the available data and publications in these areas and used them for decision making and planning. The author notes that the specialised subject areas are interweaved with components of data, information and technologies that could be used to drive their discipline. The utilisation of these variables (data, information and technologies) become vital considering the evolving nature of the knowledge required in solving problems in healthcare. Although HIs is still gaining momentum in the African context, but it is believed that many academics/scholars and healthcare or medical professionals are not passionate about digging deep into new knowledge, hence the slow growth of its knowledge cycle. However, digging deep into new knowledge has the capacity to strengthen current knowledge, as it is a key driver in present knowledge economy that underscores service delivery in healthcare or medical practices. This paper aims to address the knowledge gap in literature regarding HIs, methodological approach, contextualisation, and application of knowledge and skills in quality service delivery in healthcare profession.

HIs that are significant to this study is shown in figure 1 and 2 below. The related fields of study associated with HIs indicated in this study, is based on the research by Kazemi (n.d), Al-Rowibah (2019) and Ammenwerth (2019), where HIs is linked to computer science, information science and healthcare. The reason for this explanation was the nature of the intertwined components of data, information and technologies associated to computer science, information science and healthcare. The above-mentioned fields of study use data, information and technologies in their daily operations. The utilisation of the variables (data, information and technologies) has become vital in healthcare, higher education institutions and other related institutions. It is envisioned that, if consideration is given to the value that can be gained from a combination of niches in the associated fields, it would result in the transformation of operations that occur on a daily basis in healthcare or medical practices. The author of this paper made a clear distinction in fig 1 and 2, showing that, when addressing issues in healthcare, what is paramount is prevention, treatment and management of illness. These cannot be solved or attended to without the use of data, information and technologies. They are used by healthcare professionals on daily basis, to make assessments, diagnoses and to investigation difficulties in medical practices. In this regard, there is no organisation in present day information and digital economy, which can do without the support of considerable computer science, information science and other related technological tools. The link between how computer becomes a major influence on human become a significant interplay on data gathering, processing, storage, and use for the purpose of diverse activities both in academia and healthcare system environment. The author notes that, the integration of data, information and technologies, which encompasses the three threshold of healthcare, information science, and computer science was to unveil the mystery that sustain the improvement of quality service delivery in healthcare profession.

The essence of this research, as shown in figures 1 and 2, was for scholars in African organisations to understand where these three fields interlink and how they support each other in different research undertakings. The presentation in figure 2 indicates the various fields associated with health informatics, namely bioinformatics, 
medical informatics, clinical informatics, nursing informatics, data mining, biosciences and healthcare informatics (Kazemi, n.d, Al-Rowibah, 2019; Ammenwerth, 2019). This inspired the author of this paper to embark on this study, since HIs is a growing multidisciplinary field that could give birth to new and diverse areas of learning in the present-day knowledge evolution in Africa.

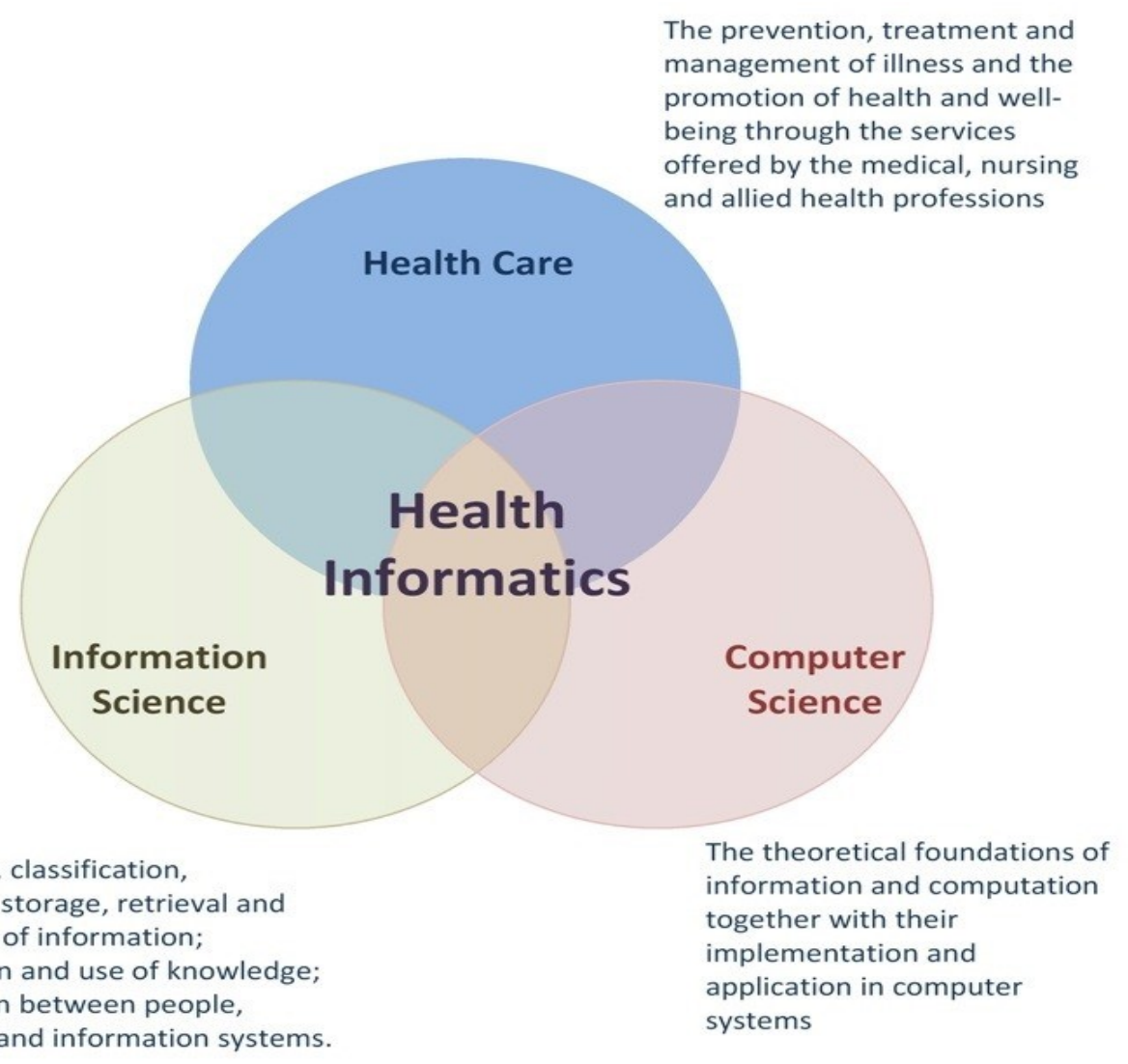

Figure 1: Health informatics and related fields of study

Source: https://www.quora.com/What-is-Health-Informatics

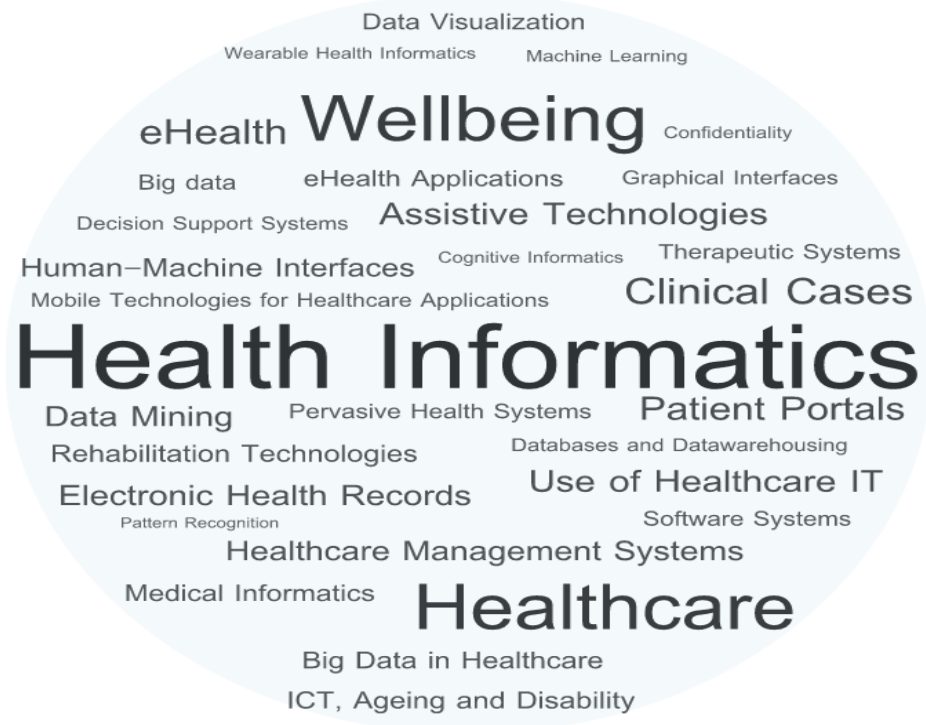

Figure 2: Health informatics and related fields of study 


\section{Literature review}

In the world of academia, much attention is given to research activities, which eventually result in the publication of research articles. The attention given to research activities has made research institutes and related teaching and learning organisations to apply the use of data, information and digital technologies as key to survival of best practices. The justification is that best practices in the medical field require extensive research and the application of the latest technological tools, which, in turn, should result in articles that are published in journals. The reflection on HIs made the author of this paper to unveil the status of health system in Africa. The essence of brining in the issue of health status in Africa was to have a clear picture of the scenario of health system in Africa, so that, dealing with HIs would not be misleading. It is obvious that several nations, across the world, are faced with diverse health challenges. This made Oleribe et al. (2019) make reference to some the challenges faced in the health system in Africa, which vary from one country to another, as emphasised with consideration to human development index (HDI). Many of the countries in Africa, over the years, have experienced different problems that include inadequate manpower and technological tools as well as the challenges caused by a lack of financial, institutional technical support and instability due to political developments (Oleribe, et al. 2019). These has affected the appropriate governance of the health system of many nations in Africa. Petersen, Marais, Abdulmalik, et al. (2017) referred to other factors that have contributed to poor service delivery in the healthcare system includes scarcity of healthcare professionals and technological tools/system support, finance and leadership. These have a great impact on the quality of healthcare services rendered to citizens. Marais and Petersen (2015) indicate that, the healthcare system has suffered a lot of challenges due to neglect and poor funding, thus leading to unforeseen challenges across diverse countries in Africa. This led to the World Health Organization (WHO) (2007) reemphasising to governments to focus on their attention on some of the factors mentioned by Marais and Petersen (2015) as they are critical in strengthening any economy health system. Based on the emphasis made by WHO (2007), the right knowledge and technological tools that could support the health system of any nation becomes essential, hence this paper, which address HIs (Al-Rowibah, 2019).

Related studies in health and the medical field, specifically focused on bibliometric analysis, has been carried out by Sullivan (2001), Onyancha and Ocholla (2009), Glover and Bowen (2004), Rotich and Onyancha (2016), Chuang, Chuang, $\underline{\mathrm{Ho}}$ and Ho (2011) and Macías-Chapula and Mijangos-Nolasco (2002); however, none of these considered HIs as a related field of study. The quantity apportioned to publication of articles in a particular field varies in context, subject and phenomenon. Several studies by Araújo, Moreira, Furtado, Pequeno, and Andrade (2014), Baby and Kumaravel (2012), Egghe (2010), Naranan (1971), Ruiz-Castillo and Costas (2014), Schorr (1974), Sudhier (2013), Suen and Yang (2012) and Torbati and Chakoli (2013) gave widespread explanations over the disparity of research output patterns and visibility of authors' research work. A follow-up research by Onyancha (2010), indicates that publication counts and analysis are progressively flattering to the global setting such that, in-depth meter of research output is counted through bibliometric analysis. The outcome of such mapping is based on a specific field where scholars' work show great significance. Therefore, this study focuses on bibliometric research methods that examine publishing patterns of health informatics in Africa, between 1987 and 2018.

This research is believed to contribute to systematic policy and research organisation in terms of inclusivity in education, knowledge sharing among researchers/scholars in specific field of study. The study would add value to the strength of scholarly communication and visibility of research output over these years, 1987 to 2018 , among academics and medical practitioners. This made Nwagwu (2006) notes that, similar studies in bibliometric has extended outside the range of publication analysis, especially in the developed world. Although some societies are yet to partake in its utilisation for strategic assembling and planning. The data and information harvested have become useful for research and other work in academia. The author of this paper contemplated on why healthcare professionals and associated scholars in Africa are no longer passionate about digging deep into new knowledge. Possible reasons could be that there is no propelling force, no incentives, no conducive work environment and possibly no facilities. Therefore, to actualise this, individuals in this healthcare and medicine need to be encouraged to actively source the information, data and technologies required in healthcare services. Through the support of technologies, the required information or data can be obtained from different sourced, processed, stored, retrieved and utilised for patient diagnosis (Healthcare Administration Degree Programs, n.d).

In light of the above, the author of this study concluded that HIs is an interdisciplinary area of study that trails the active use of biomedical data, information and know-how for systematic inquiry in order to solve human 
health situations and to make concrete decisions to advance daily living. HIs is not concerned with the use of the technological tools only, rather it advances quality healthcare delivery through proper adherence to policies, acquisition and accessibility, and the monitoring and maintaining those technological tools required to care for the patient and other related work in healthcare organisations (Ammenwerth, 2019). The application of different procedures for the gathering of information could be used within and outside healthcare institutions. The application of HIs became necessary due to different ailment affecting human beings today around the world and specifically in Africa. The desire for in-depth knowledge in HIs has made researchers and scholars strive to find better ways to articulate and handle job specifications in the world today. Many healthcare organisations and higher education institutions in Africa, where medical practitioners are trained, have adopted the application of HIs in their operations and service delivery. This was to advance best medical practices and teaching and learning carried out in these institutions.

Ammenwerth (2019) emphasises that the formation of knowledge in Hls among scholars could propel how efficient and effective they were in provision of quality services to human being in general. Evidence-based research by Park (2016) and Turner, Kushniruk and Nohr (2017), and Ammenwerth (2019) indicate that HIs serves as interference for healthcare and in bio-medical domains where health professionals and scholars progressively advance their practices for improved patient care through a number of digital information systems. The information systems tools in question comprises artificial intelligence, robotics, the Internet of Things, smartphones, electronic medical records, portable medical devices and wearable computing, among others. These technological tools are used by physicians and other scholars to harvest the data and information required for further collection, analysis and exchange, for the purpose of delivering quality services. Technology has made life much easier for health professionals and scholars, such that, they no longer struggle to interpret data and information collected to enhance their service delivery (Park, 2016; Turner, Kushniruk and Nohr, 2017; Ammenwerth, 2019). To this end, medical practitioners and other scholars in related fields could apply their experiences and knowledge to answer difficulties in health issues. With Hls, it is possible to identify tendencies that could have brought about a scenario and it proposes insights on how the health condition of the individual could be addressed. It progresses from generating information and data through diagnosis and different test analysis, in order to reduce costs and medical error (Ammenwerth, 2019). Apart from medical practitioners, pharmacists, bioinformatics and life scientists, who uses different tools in carrying out series of medical test in the hospital, academics now fully deepened on them in their research investigation. The author of this study emphasises that, HIs is of importance to humanity, thus, creating an opportunity for maintenance culture that propels the use of technological tools to advance research and support medical practices in Africa and globally. Although, this maintenance culture practice is still a challenge in Africa. The maintenance culture practices can be actualised through first reading or studying the manual of the various tools and gaining an understanding of how the tools could be used by any individual and what it is used for.

The job descriptions associated with the various HIs applications range from the requirement of data filtration, assembly, handling, modelling, software development, repairs of clinical databases, execution of health IT software tools, continuous training and re-training of professionals (Turner, Kushniruk and Nohr, 2017). Turner, Kushniruk and Nohr (2017) further note that data analytics are now part of HIs, thus, drawing distinction on management operations of how valuable data and information is to services carried out in the hospitals. This does not mean that those without knowledge of or a background in computers cannot migrate to Hls, all that is required is determination and regular training in order to adapt to and adopt the ethical protocols and practices. The understanding of the authors with regard to the technological tools used in HIs is that, when diagnosing a patient with an ailment, for example, asthma, the health professional makes use of the tool to find out how the symptom could be traced and treated (Sullivan, 2001). This is also applicable to other ailments such as HIV, tuberculosis and cancer (Sullivan, 2001). The tools for different ailments or diseases differ as well. Therefore, HIs tools are also used to do follow-up diagnoses (Sullivan, 2001).

Hls, as mentioned earlier, has had a significant and transformational impact on healthcare service delivery across the globe, in diverse contexts (Greenes and Shortliffe, 1990; Smith, 1997; Morris and McCain, 1990; Detmar, 2000; Tierney, 2001; Park, 2016; Turner, Kushniruk and Nohr, 2017; Ammenwerth, 2019). The transformational and significant differences are centred on the efficiency and effectiveness of the tool, combined with the experience and knowledge of the health professional, which are harnessed to diagnose an ailment; allows for the easy capturing and retrieval of patient data on electronic databases; a practical presentation and integration of information to interpret patient problems; minimises the workload required to search for relevant materials, the prescription of medications issued to the patient and confirmation of when next to visit the hospital again 
due to the application of the HIs medical tools (Greenes, 1990; Smith, 1997; Morris and McCain, 1990, Detmar, 2000; Tierney, 2001; Park 2016; Turner, Kushniruk and Nohr, 2017; Ammenwerth, 2019). The authors established that the utilisation of computerised systems in any health institution and related organisation would improve the work performance of both physicians and academics/scholars. Therefore, a bibliometric analysis of HIs in Africa could assist massively, contributing to improving services in the healthcare sector. There is no nation in the world that do not pay attention to quality healthcare services, especially consideration to costeffectiveness on human fitness. This was based on personal observation and experiences of the author in the context of Africa. Many people in Africa are still ignorant of what to do and possibly where to go when they are faced with health challenges. Studies by Ebermann (2016); Sodi, Mudhovozi, Mashamba, Radzilani-Makatu, Takalani and Mabunda (2011) and Owusu-Ansah and Mji (2013) indicate that the use of indigenous knowledge (IK), or herbal treatment, is still very prominent in many African communities. This is another indication of why this present study require broader strengthening and engagement in dialogue with health practitioners and scholars on best practices in healthcare service delivery being promoted in Africa. Although IK regards herbal treatment as useful and best practices in medical treatment. Therefore, it should not be undermined, as there are indications of proof in sustainability of healthcare services. This could result in test and verifiable analysis that can be carried out by health practitioners.

\section{Purpose of the study}

The purpose of this study was to apply bibliometric research strategies to investigate the publishing patterns of health informatics study in Africa, in the last thirty-one years, 1987 to 2018 . This was guided with the following specific research objectives:

- $\quad$ analyse publication counts, by year, between 1987 and 2018

- identify the avenue through which HIs publications were communicated

- categorise the distribution of HIs records by authorship

- identify the top producing authors in HIs and their different subject areas

- $\quad$ find out the top journals where HIs papers are published

- identify the top subject areas publishing HIs papers in Africa

- classify the country and institutional affiliation that publishes HIs papers in Africa

- identify the funding bodies responsible for HIs publishing in Africa

\section{Research methodology}

Presently, in research investigation, different approaches are applied to harvest research data from databases. This phenomenon of harvesting data from databases is associated with bibliometric analysis of publication and their citation impact is of immerse significance to scholars and the results of various studies. This type of research, where the researcher has to do a lot of searches when making inquiry about a particular phenomenon, can be likened to the exploratory research approach (Saunders, Lewis and Thornhill, 2009). The exploratory process leads to the gathering of information based on certain ideas that the researcher has in mind. The essence of the exploratory process makes reference and citation of publication, where distinction on certain research work has been carried out over a period of time. The purpose of analysing the HIs publications was to establish the research impact, visibility and output of academics. This would help promote scholarly communication, knowledge sharing and contribution to existing knowledge in the particular field of study. The basis was to ascertain whether the area of study is advancing or retarding and, if so, to offer solutions. The Scopus database was used to extract documents (data) on HIs studies in Africa, from 1987- 2018. The study covered a period of thirty-one (31) years of published articles in HIs, in Africa. During the course of the search strategy, the author applied the search option of "Health Informatics", and "Africa". The duration of the study was three weeks, from when the data was harvested and collated to when it was analysis, presented in tables and discussed. The results obtained showed that there were 2332 documents or research papers published over this period. The Scopus database was used because there is no actual local database that indexes literature in the field of HIs in Africa. Scopus is the second largest database that houses documents in library and information science area of specialisation where HIs studies is resident. The use of Scopus for extraction of data or published works/documents on HIs became necessary, since many scholars have also worked on this related field of study, as mentioned above.

\section{Results}

The results obtained from this study was based under the following subheadings:

- $\quad$ publication counts by year from 1987 to 2018 
- $\quad$ avenue through which publications in HIs were communicated

- records by authorship

- top producing authors in HIs and their subject area

- top journals where HIs papers are published

- productivity by country and institutional affiliation

- funding sponsor

\subsection{Publication counts by year from 1987 to 2018}

The publication counts, from 1987 to 2018, measured in various document types in Scopus databases resulted in 2332 research output. This indicates that the number of HIs articles published in Scopus journals were 2332. The line graph, in figure 1 below, indicates that between 1987 to 2002, there was not a significant increase in the number of publications in HIs in Africa. It can be deduced that this was due to a scarcity of information regarding this area of specialisation in Africa. Although, it is possible scholars where involved in research activities, their work was not visible online. Interestingly, a changed occurred immediately after 2002 to date, as represented below. This shows that scholars are now publishing in this area and that their work is also visible online. Sometimes, it is difficult to ascertain the extent to which research work is on-going when there is no reporting on those studies. The author's research affirms that, not all journals published by higher education institutions and other bodies are published online. In this regard, it becomes difficult and, sometimes, even impossible to harvest those resources published in hard copy. The Scopus databases is only able to harvest resources published online and also those indexed by the Scopus database.

\section{Documents by year}

Publication counts per year

500

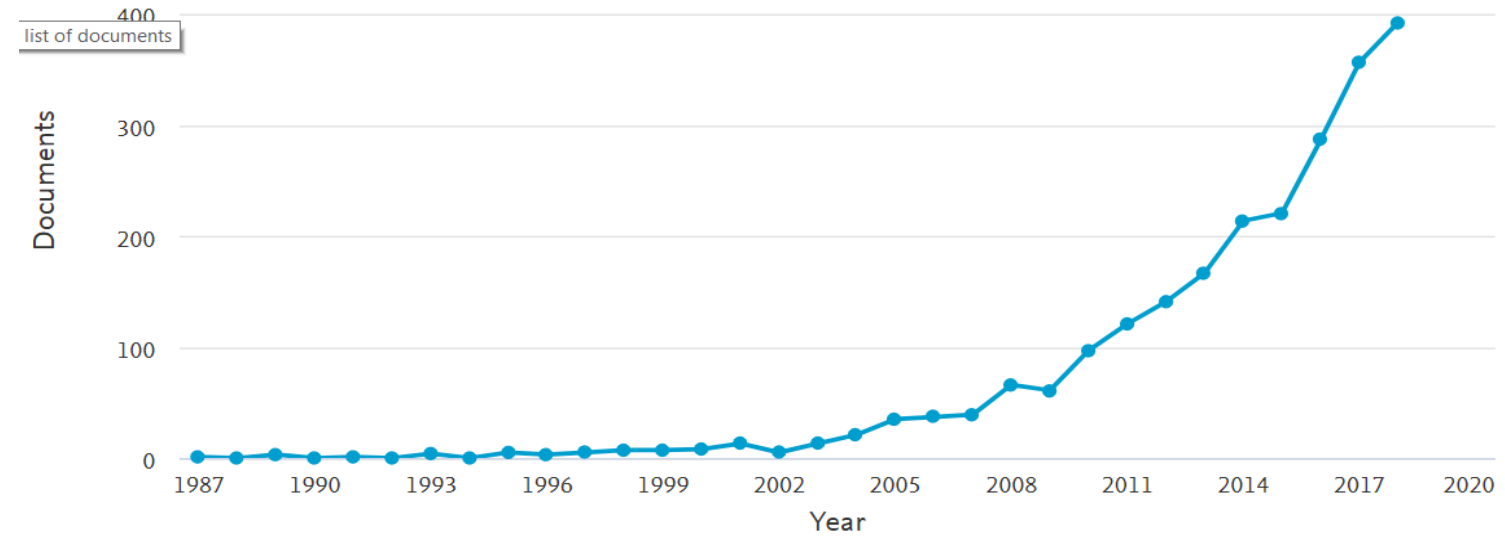

Figure 3: Publication counts per year

\subsection{Representation of publications by year through percent}

The results obtained in this segment were measured in their numbers of publication and percent. Table 1 shows that in the years 1980,1990, 1992 and 1994, there were no publications on HIs research recorded. However, the most interesting part is the results obtained between 2004 and 2018, which were very encouraging. The findings were as follows: $2018=393(16.85 \%), 2017=357(15.31 \%), 2016=287(12.31 \%), 2015=221(9.48 \%), 2014$ =214(9.18\%), $2010=97(4.16 \%), 2009=61$ (2.62\%), 2008 = 66 (2.83\%), 2007 =39 (1.67\%), 2006= 37 (1.59\%), $2005=35(1.51 \%), 2004=21(0.90 \%)$. This indicate that, HIs areas of study is advancing progressively. The reason could be attributed to many scholars publishing in this area of study, as more awareness are being created in the underlying information science discipline. 
Table 1: Publication counts per year Scopus $(N=2,332)$

\begin{tabular}{|l|c|c|}
\hline Publication year & Record count & \% \\
\hline 2018 & 393 & 16.85 \\
\hline 2017 & 357 & 15.31 \\
\hline 2016 & 287 & 12.31 \\
\hline 2015 & 221 & 9.48 \\
\hline 2014 & 214 & 9.18 \\
\hline 2013 & 167 & 7.16 \\
\hline 2012 & 141 & 6.04 \\
\hline 2011 & 121 & 5.19 \\
\hline 2010 & 97 & 4.16 \\
\hline 2009 & 61 & 2.62 \\
\hline 2008 & 66 & 2.83 \\
\hline 2007 & 39 & 1.67 \\
\hline 2006 & 37 & 1.59 \\
\hline 2005 & 35 & 1.51 \\
\hline 2004 & 21 & 0.90 \\
\hline 2003 & 13 & 0.56 \\
\hline 2002 & 5 & 0.21 \\
\hline 2001 & 13 & 0.56 \\
\hline 2000 & 8 & 0.34 \\
\hline 1999 & 7 & 0.30 \\
\hline 1998 & 7 & 0.30 \\
\hline 1997 & 5 & 0.21 \\
\hline 1996 & 3 & 0.13 \\
\hline 1995 & 5 & 0.21 \\
\hline 1994 & 0 & 0.0 \\
\hline 1993 & 4 & 0.17 \\
\hline 1992 & 0 & 0.0 \\
\hline 1991 & 1 & 0.04 \\
\hline 1990 & 3 & 0.0 \\
\hline 1989 & 0 & 0.13 \\
\hline 1988 & 1 & 0.0 \\
\hline 1987 & & 0.04 \\
\hline & 0 & \\
\hline & 5 & 37 \\
\hline
\end{tabular}

\subsection{Avenue through which publications were communicated}

This segment considered the avenue through which publications were communicated over the thirty-one years (1987-2018) of bibliometric analysis of articles harvested from the database. The results obtained indicate that research articles 1562 (66.98\%), published in journals, was the highest; followed by conference papers, with 394 (16.89\%); reviews, with 224 (9.61\%); book chapters, with 58 (2.49\%); and then editorial papers. Letters, conference reviews and short surveys were minimal. It therefore means that the majority of the research in HIs are presented in research articles, conference papers and reviews. The reason could be that most of the scholars in this area are academics and medical practitioners. It is likely that recent research findings on topical issues would appear in research articles, conference papers and reviews. More importantly, since HIs is associated with medical practices, there are many activities which could propel individuals to be active in writing and who would also want to promote scholarship and knowledge sharing. It is not out of place if people do not want to communicate their work in book chapters, editorials, letters, conference reviews and short surveys. Sometimes, book chapters, editorials, letters and short surveys are not fully recognised by institutions, compared to articles and conference papers. In recent times, articles and conferences papers are rated as the major platforms for academics and scholars to earn points regarding promotion criteria and the increase in the number of papers can also be attributed to collaborative efforts. 
Table 2: Avenue through which publications were communicated

Scopus $(\mathrm{N}=2,332)$

\begin{tabular}{|l|c|c|}
\hline Avenue & Record count & \% \\
\hline Article & 1562 & 66.98 \\
\hline Conference paper & 394 & 16.89 \\
\hline Review & 224 & 9.61 \\
\hline Book Chapter & 58 & 2.49 \\
\hline Note & 20 & 0.85 \\
\hline Book & 17 & 0.73 \\
\hline Editorial & 15 & 0.64 \\
\hline Letter & 14 & 0.60 \\
\hline Conference review & 12 & 0.51 \\
\hline Short survey & 9 & 0.39 \\
\hline Erratum & 2 & 0.09 \\
\hline
\end{tabular}

\subsection{Records by authorship}

The findings presented in figure 2 indicate that, between 1987 and 2018, Tomlinson was at the top of the list of published authors, with 26 publications, followed by Hay (25 publications), Farzadfar (21 publications), WoolsKaloustian (21 publications), Lopez (19 publications), Murray (19 publications), Tierney (19 publications) and Yonemoto (19 publications). The findings show that, to have an adequate number of papers published depends on several factors, such as a conducive working environment, including an office space; funding to attend conferences/workshops and seminars; access to internet facilities; a good collaboration team and drive from the individual researcher. One would expect that, over time (in this case, 31 years) there would have been a substantive number of quality papers published. However, based on the author's own experience, many academics are not driven when it comes to research activities, as it takes a lot of rigour and interest to produce research papers. Importantly, many academics are emerging researchers, who require mentorship and support from their peers and organisations.

Documents by author

Compare the document counts for up to 15 authors.
Publication counts per author

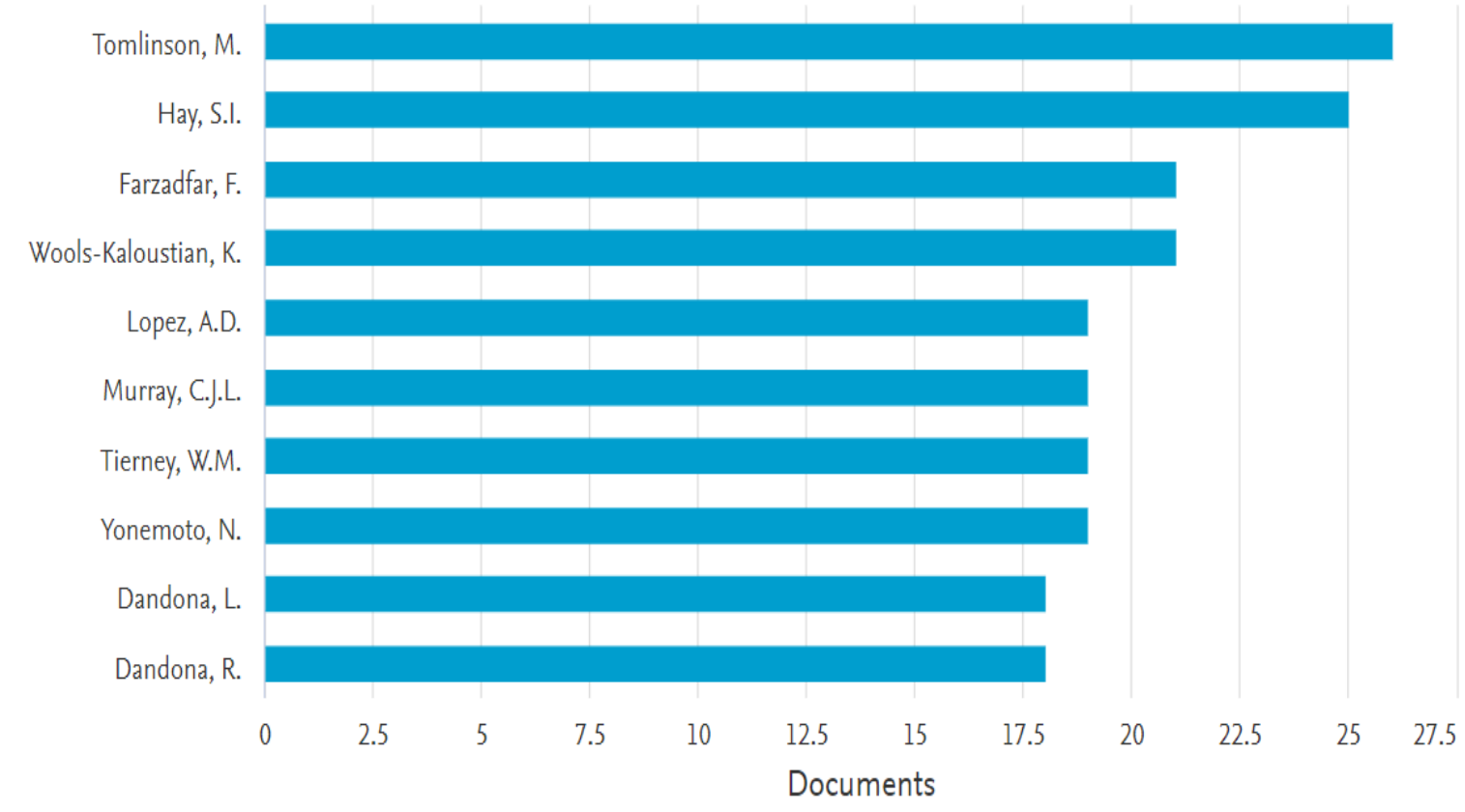

Figure 4: Documents by authors 


\subsection{Top producing authors}

This section establishes the top producing authors in HIs research publication between the period, 1987 to 2018 , which is the focus in this investigation. The results in table 3 indicate the top producing authors as far HIs publications is concerned, namely Tomlinson (26, 1.11\%), Hay (25, 1.07\%), Farzadfar (21, 0.90\%), WoolsKaloustian (21, 0.90\%), Lopez (19,0.90\%), Murray (19, \%), Tierney (19, \%) Yonemoto (19, \%), Dandona (18, $0.77 \%)$, Gething $(18,0.77 \%)$, Kengne $(18,0.77 \%)$, Khang $(18,0.77 \%)$, Rafay $(18,0.77 \%)$, Salomom $(18,0.77 \%)$, Terkawi $(18,0.77 \%)$ and Ukwaja (18, 0.77\%). These publications were achieved through the effort of the authors, either individually or through collaborative efforts, in their different areas of specialisation. Many of these authors had to invest a considerable amount of time, effort and patience to ensure that their papers are published in reputable journals. Publishing research papers is part of the responsibility of academics in order to promote scholarship and knowledge sharing. They are also required to publish before they can be assessed and considered for promotion. The author expects that there were certain requirements that these academics would have had to embark on their research project, like the provision of internet facilities, a workable office space and other support from their organisation.

Table 3: Top producing authors from1987-2018

Scopus $(\mathrm{N}=2,332)$

\begin{tabular}{|l|c|c|}
\hline Authors & Record count & \% \\
\hline Tomlinson & 26 & 1.11 \\
\hline Hay & 25 & 1.07 \\
\hline Farzadfar & 21 & 0.90 \\
\hline Wools-Kaloustian & 21 & 0.90 \\
\hline Lopez & 19 & 0.81 \\
\hline Murray & 19 & 0.81 \\
\hline Tierney & 19 & 0.81 \\
\hline Yonemoto & 19 & 0.81 \\
\hline Dandona & 18 & 0.77 \\
\hline Gething & 18 & 0.77 \\
\hline Kengne & 18 & 0.77 \\
\hline Khang & 18 & 0.77 \\
\hline Rafay & 18 & 0.77 \\
\hline Salomom & 18 & 0.77 \\
\hline Terkawi & 18 & 0.77 \\
\hline Ukwaja & 18 & 0.77 \\
\hline
\end{tabular}

\subsection{Top subject areas}

The findings presented in figure 3 show that Medicine (35.9\%) was at the top of the list of subject areas in the publications of HIs. The rest of the discipline had some components of HIs, such as Computer Science (10.2\%), Social Science (9.5\%), Biochemistry (6.1\%), Engineering (5.6\%), Agricultural (5.0\%), Health profession (4.2\%), Immunology (3.7\%), Environmental Science (2.7\%) and Business Management (2.6\%), while unrelated discipline, "Others" accounted for $14.4 \%$. A likely explanation for this is that HIs is associated with the collection of data and utilisation of technological tools. Several of the disciplines identified below form part of HIs and also make use of related research data and tools in their investigation and problem-solving mechanisms. Today, knowledge discovery, in any discipline, cannot be embarked on without the use technological tools in regard to data collection and processing, as well as the storing of data in order for it to be used for diverse research purposes. The author holds that, as different subject areas continue to emerge, the use of data and technological tools will be needed to advance transformation of job description and investigations. 


\section{Documents by subject area}

Publication counts by subject area

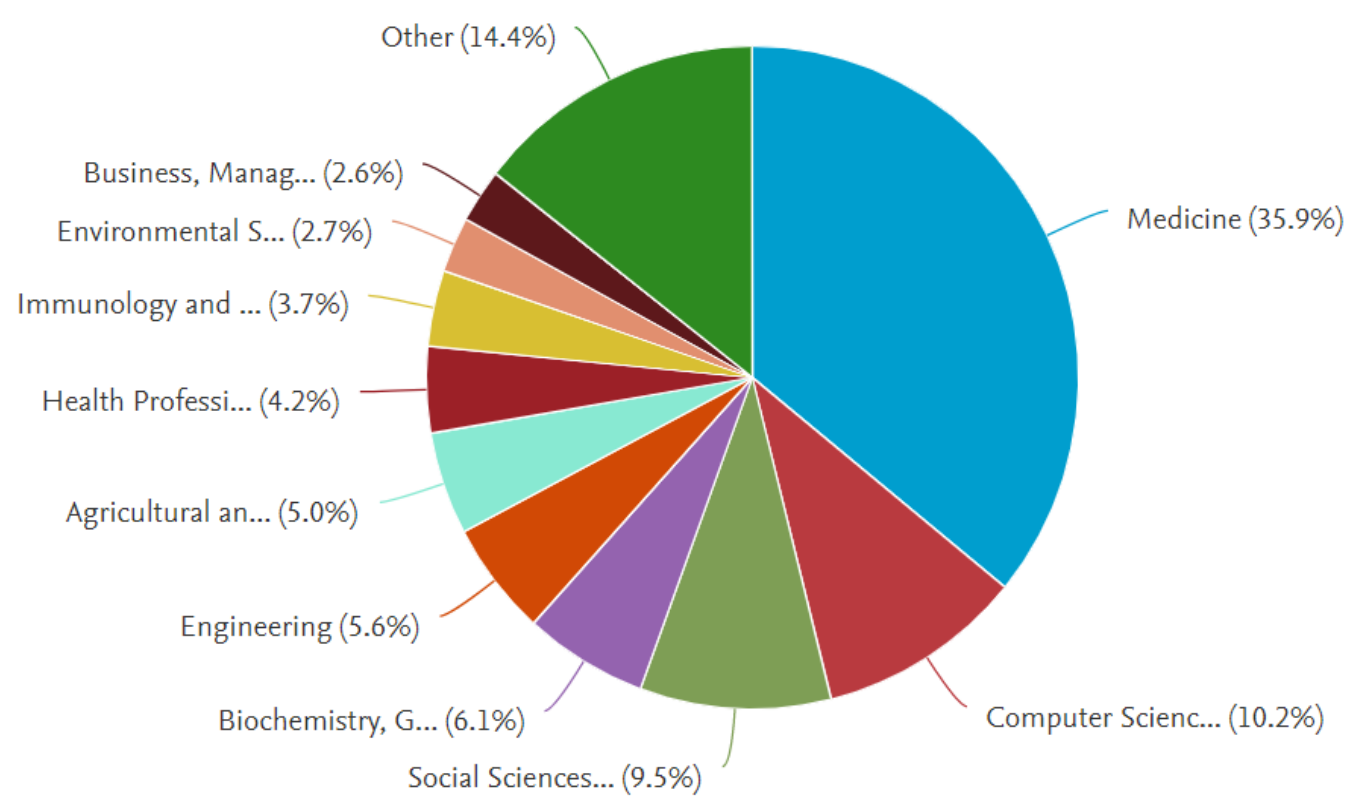

Figure 5: Document by subject areas

\subsection{Top journals where Hls papers are published}

In this segment, the author identified the top journals wherein papers in HIs were published. The findings indicate that these were categorised according to their ranking, as presented in table 4 below. Plos One (84, $3.60 \%$ ) was the first, followed by Lancet (34, 1.46\%), the International Journal of Medical Informatics (30, 1.29\%), South African Medical Journal (26, 1.11\%), BMC Public Health (25, 1.07\%), ACM International Conference Proceeding Series (23, 0.98\%), BMC Health Services Research (23,0.98\%), Lecture Notes of the Institute for Computer Science (21, 0.90\%), Informatics and Telecommunication Engineering (21,0.90\%), BMC Medical Informatics and Decision making (20,0.86\%) and Global Health Action (20,0.86\%). It can be deduced that these journal publications are mainly focused on healthcare and medical practice. Interestingly, HIs is part of the health profession; hence, most scholars prefer to publish their work there. Journals in health area of specialisation are of great significance due to the evolving nature of research investigation and topical issues discussed in those areas. Another reason why scholars/academics or health professionals publish in some of the listed health journals below is due to their h-index factor, which measures both the productivity and citation impact of a publication. For scholars/researchers' work to be well rated and valued, it has to published in h-impact factor journals. The author also believe that it is imperative that, to stay relevant in a discipline, researchers have to stay abreast of recent trends and be seen to contribute to field through research and publishing in health-related journals, like some of those mentioned below. 
Table 4: Top journals wherein HIs papers are published

Scopus $(\mathrm{N}=2,332)$

\begin{tabular}{|l|c|c|}
\hline Journals & Record count & \% \\
\hline Plos One & 84 & 3.60 \\
\hline Lancet & 34 & 1.46 \\
\hline International Journal of Medical Informatics & 30 & 1.29 \\
\hline South African Medical Journal & 26 & 1.11 \\
\hline BMC Public Health & 25 & 1.07 \\
\hline ACM International Conference Proceeding Series & 23 & 0.90 \\
\hline BMC Health Services Research & 23 & 0.98 \\
\hline Lecture Notes of the Institutive for Computer Sciences & 21 & 0.90 \\
\hline Informatics and Telecommunications Engineering & 21 & 0.90 \\
\hline BMC Medical Informatics and Decision making & 20 & 0.86 \\
\hline Global Health Action & 20 & 0.86 \\
\hline
\end{tabular}

\subsection{Productivity by countries in Africa}

The findings, as indicated in table 5, identified the various countries in Africa where publications in HIs are published. It can be seen that South Africa $(923,39.6 \%)$ was at the top of the list with the highest number of papers published in HIs, followed by Kenya (181, 7.76\%), Nigeria (141,6.04\%), Ghana (110, 4.71\%), Uganda (110, $4.71 \%)$, Tanzania (85, 3.64\%), Cameroon (67, 2.87\%), Ethiopia (64, 2.74\%), Malawi (56, 2.40\%), Rwanda (51, $2.18 \%)$ and Zambia $(48,2.06 \%)$. While the countries with least number of publications in HIs are Lesotho (5, $0.21 \%)$, Niger (5, 0.21\%), Liberia (4, $0.17 \%)$, Madagascar $(4,0.17 \%)$, Djibouti $(2,0.09 \%)$, Equatorial Guinea ( 2 , $0.09 \%$ ) and Chad $(1,0.04 \%)$. The findings were all categorised according to their ranking of production of papers by each country, as presented in table 5 below. The author assumes that countries like South Africa, Kenya, Nigeria, Ghana, Uganda, Tanzania, Cameroon, Ethiopia, Malawi, Rwanda and Zambia are at the top of the list because their governments support higher education institutions through the provision of adequate funding and infrastructural facilities; hence, the growth rate of research publications.

The South African government promotes a functional and active healthcare services, which drives an interest in healthcare research among many scholars and healthcare professionals. These assumptions are derived from the author's experiences and observations while studying towards his doctorate and living in South Africa for over seven (7) years. In the case of the countries where there have been limited publications, it could be that the government in those countries do not provide adequate funding for their higher education institutions and, therefore, these institutions are unable to attract researchers interested in pursuing research endeavours that would lead to published papers. It is also possible that some of the countries mentioned (Lesotho, Niger, Liberia, Madagascar, Djibouti, Equatorial Guinea and Chad) are still very backward in terms of growth, visibility, research output and development and in fostering scholarship; hence, the limited numbers of papers. The author also gathers that governments and higher education institutions in these countries would have challenges with regard to the provision of a conducive working environment, electricity, the internet and other ICT facilities that could support research and advance scholarship; hence, scholars/researchers do not have the drive to embark on research and publication. More importantly, the author concludes by suggesting that to advance scholarship, some of the factors previously mentioned, like policy implementation and the provision for a conducive environment and infrastructural support, must be provided in research investigation before advances can be made among scholars. 
Table 5: Productivity by countries in Africa

Scopus $(\mathrm{N}=2,332)$

\begin{tabular}{|c|c|c|}
\hline Countries & Record count & $\%$ \\
\hline South Africa & 923 & 39.6 \\
\hline Kenya & 181 & 7.76 \\
\hline Nigeria & 141 & 6.04 \\
\hline Ghana & 110 & 4.71 \\
\hline Uganda & 110 & 4.71 \\
\hline Tanzania & 85 & 3.64 \\
\hline Cameroon & 67 & 2.87 \\
\hline Ethiopia & 64 & 2.74 \\
\hline Malawi & 56 & 2.40 \\
\hline Rwanda & 51 & 2.18 \\
\hline Zambia & 48 & 2.06 \\
\hline Egypt & 43 & 1.84 \\
\hline Burkina Faso & 38 & 1.63 \\
\hline Mali & 36 & 1.54 \\
\hline Botswana & 34 & 1.46 \\
\hline Mozambique & 34 & 1.46 \\
\hline Congo & 32 & 1.37 \\
\hline Zimbabwe & 31 & 1.32 \\
\hline Benin & 27 & 1.16 \\
\hline Cote d'Ivoire & 22 & 0.94 \\
\hline Namibia & 22 & 0.94 \\
\hline Tunisia & 22 & 0.94 \\
\hline Senegal & 17 & 0.73 \\
\hline Morocco & 15 & 0.64 \\
\hline Gambia & 13 & 0.56 \\
\hline Togo & 13 & 0.56 \\
\hline DR Congo & 11 & 0.47 \\
\hline Sudan & 10 & 0.43 \\
\hline Sierra Leone & 9 & 0.39 \\
\hline Angola & 7 & 0.30 \\
\hline Burundi & 7 & 0.30 \\
\hline Gabon & 7 & 0.30 \\
\hline Swaziland & 7 & 0.30 \\
\hline Libyan Arab Jam & 6 & 0.26 \\
\hline Mauritius & 6 & 0.26 \\
\hline Lesotho & 5 & 0.21 \\
\hline Niger & 5 & 0.21 \\
\hline Liberia & 4 & 0.17 \\
\hline Madagascar & 4 & 0.17 \\
\hline Djibouti & 2 & 0.09 \\
\hline Equatorial Guinea & 2 & 0.09 \\
\hline Chad & 1 & 0.04 \\
\hline
\end{tabular}

\subsection{Productivity by institution affiliation}

In order to ascertain the institution of affiliation that published in HIs, documents were segmented into bites and the analysed research publications further scrutinised. The results in figure 4 indicate that the University of Cape Town (128 publications) is at the top of the list in Africa, followed by the University of Witwatersrand (171), South African Medical Research Council (160 publications), University of Stellenbosch (152 publications) and University of KwaZulu-Natal (130 publications). The reason why these affiliated institutions were at the top is because they are top-rated institutions in Africa, with a high-impact factor when it comes to research and visibility of research output. Interestingly, these institutions are fully supported by their government, with adequate financial support and ICT facilities, which is required for any research activity. It can also be deduced that most of the scholars/researcher at these institutions collaborated with others within and outside of their institutions; hence, the increase in collaborative studies over the years. It can also be noted that there were affiliations with external institutions such as the London School of Hygiene and Tropical Medicine (90), Harvard Medical School (81) and Karolinska Institute (80). Research collaboration has become a mechanism of strengthening research and a means to address the needs of researchers, where there are limited resources, 
made easier with the current technologies at the disposal of researchers at all institutions. These institutional affiliations have the added advantage of creating more visibility with regard to researchers' work, globally, and of having high impact within and across other institutions.

\section{Documents by affiliation}

Compare the document counts for up to 15 affiliations.

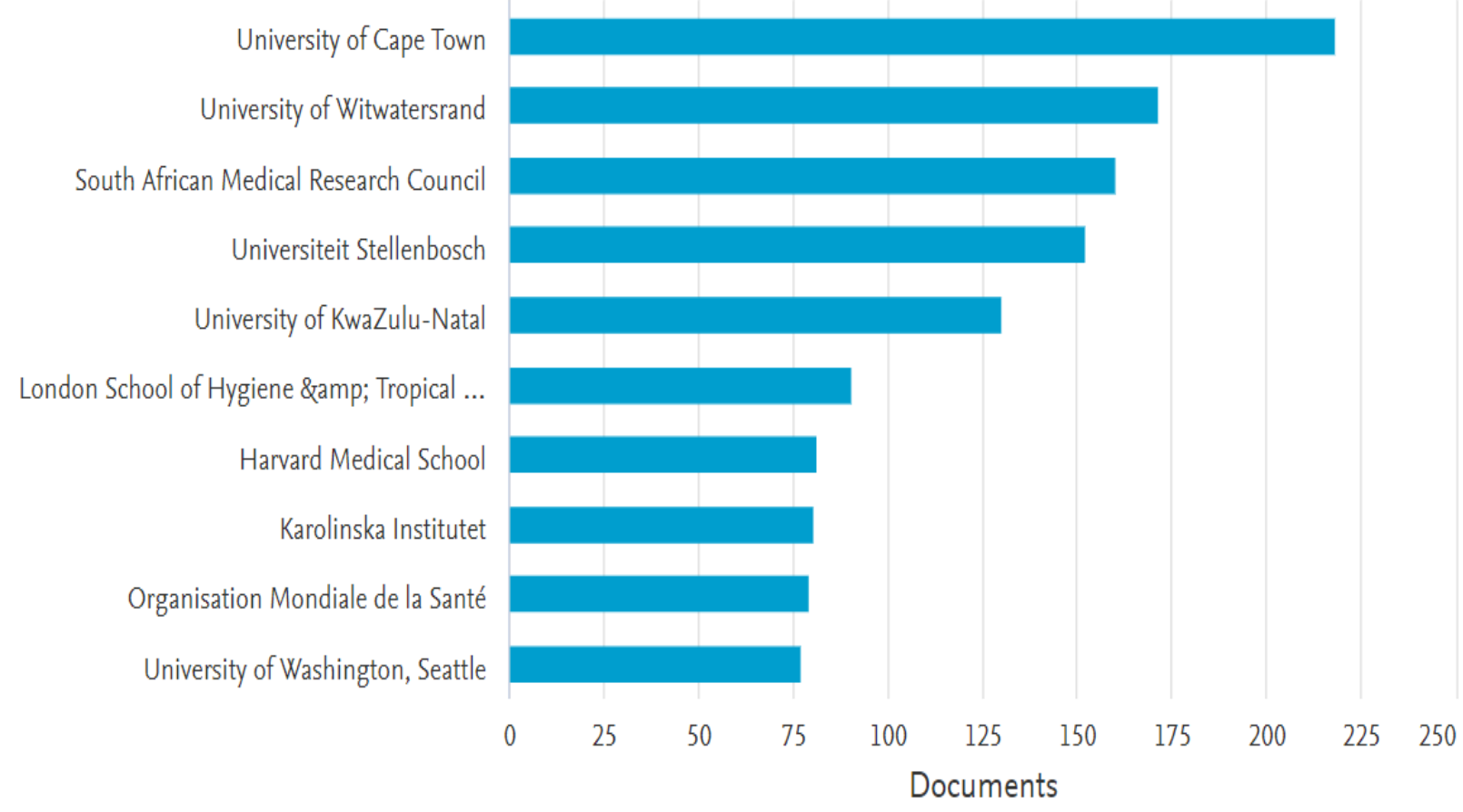

Figure 6: Productivity by institution affiliation

\section{Funding bodies}

This segment reports on the funding bodies within and outside of Africa that necessitated the possibility of publication of researchers in the areas of HIs in Africa. It can be noted, from the data presented in figure 5 below, that the National Institutive of Health was the top in the list of organisations that sponsored research activities that resulting in publications from institutions in Africa, followed by the South African Medical Council, United States Agency for International Development, Bill and Melinda Gates Foundation, National Institute of Allergy and Infectious Diseases, National Research Foundation, well come Trust, National Institute of Mental Health, Foundation for the National Institute of Health and Fogarty International Centre. The different organisations mentioned are international organisations or research-related institutions that support research activities in Africa. The nature of these organisations is such that they are also supported with adequate funding, including the governments in their various countries. Another point of emphasis is that many of the sponsored bodies are affiliated to international health institutions that promote scholarship and research activities across the world. Research activities is rigorous and without adequate infrastructural facilities and funding, it becomes difficult to engage in such an endeavour. Interestingly, due to engagement of and evolving nature of scholarship, many health research institutions are supporting research in order to arrive at new findings that would shape the society and create a better life for communities. 


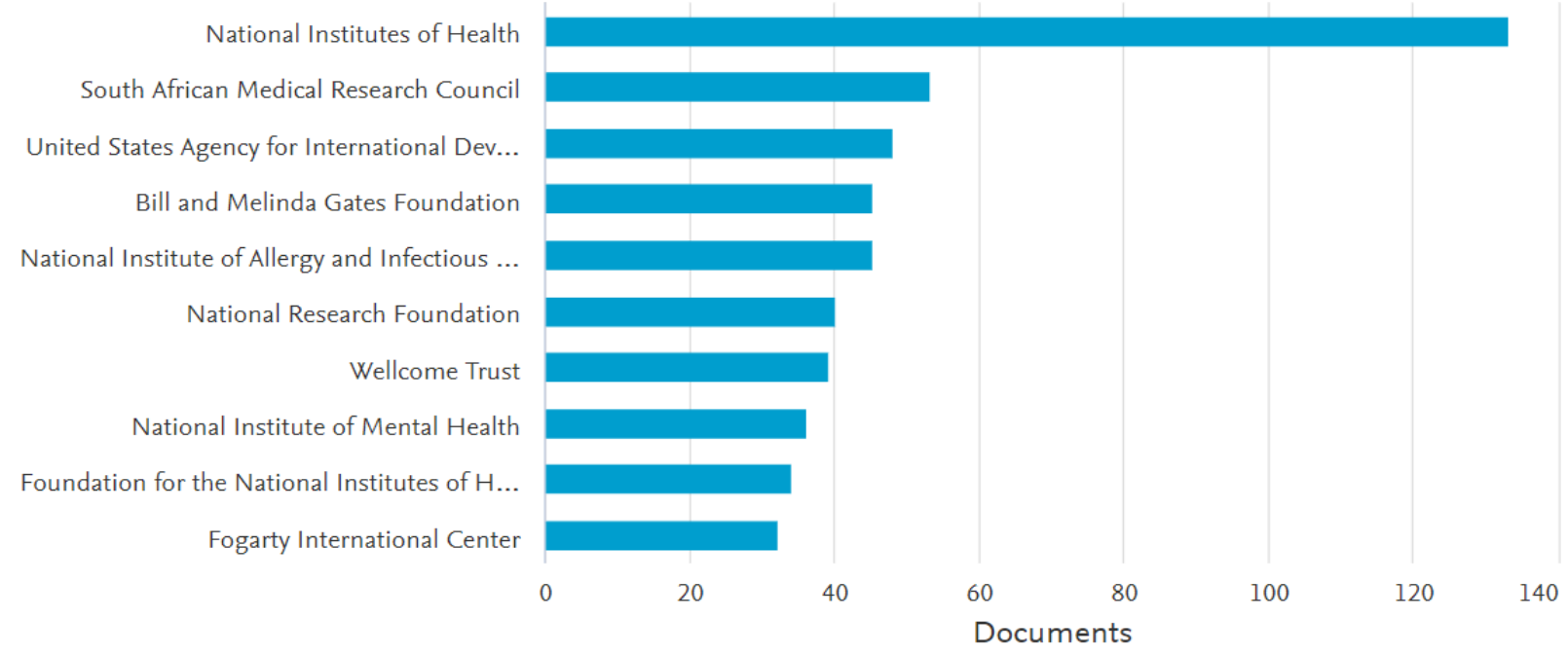

Figure 7: Funding sponsor

\section{Discussion}

The major focus of this study was to assess the publication patterns on the topic of HIs across Africa. This study succeeded in establishing existing gaps in the publications on HIs, published over the past thirty-one years, between 1987 and 2018, in Africa. The efficacy of Hls knowledge has become important in the considerations of health interventions for humankind across the world. The methodological approach was another important factor, as not all research considers harvesting data from databases such as Scopus and related scholarly sources. The reason behind this is that not all African journals are visible on this online platform. Therefore, the need to evaluate their sources becomes crucial. Presently, there is a growing trend to also give recognition to HIs papers produced in Africa, as shown in table 1. Based on the analogy of empirical studies by Al-Rowibah (2019), Ammenwerth (2019) and Araújo et al. (2014), it was noted that, Hls encompasses healthcare services, which account for other unprecedented areas of endeavours.

The results of this study indicate that there has been a tremendous shift from 2002 till 2018. This could be because the field of HIs is becoming well-known and scholars/academics have shown more of an interest in this field. It is likely that some scholars/academics in Africa were involved in some work that necessitated the visibility of result on Scopus. It is expected that, the provision of adequate resources like ICT facilities and infrastructure, as well as a conducive working environment for researchers, could facilitate significant research in this area. The study found out that most of the publications harvested were communicated through research articles, followed by conference papers, book chapters and editorial papers. The reason could be because most of the scholars/academics and medical practitioners would like to share their knowledge irrespective of the platform. Since HIs is a topical issue, most of research findings are likely to appear in research articles, conference papers and reviews. Importantly, since HIs is associated with medical practices, this could motivate individuals to be actively involved in writing research papers and promote scholarship and knowledge sharing. It was revealed that the Tomlinson, Hay, Farzadfar, Wools-Kaloustian, Lopez, Murray, Tierney and Yonemoto (19 publications) were the most prolific writers between 1987 and 2018. It can be noted that most of the authors were from renowned institutions of learning in Africa. Most of them have collaborated with institutions abroad; hence, the high volume of papers. The HIs papers were mostly on the subjects of medicine, computer science, social sciences, biochemistry, engineering, the health profession, immunology, environmental science and business management. The reason for this could be attributed to the fact that most of these subject areas are related to the health profession and computer science. The study indicates that Plos One, Lancet, the International Journal of Medical Informatics, South African Medical Journal, BMC Public Health, ACM International Conference Proceeding Series, BMC Health Services Research, Informatics and Telecommunication Engineering and BMC Medical Informatics and Decision making were the top journals, with high impact value that publishes research papers in HIs in Africa. The papers were mostly from South Africa, followed by Kenya, 
Nigeria, Ghana Uganda, Tanzania, Cameroon, Ethiopia, Malawi, Rwanda and Zambia. Unfortunately, countries like Lesotho, Niger, Liberia, Madagascar, Djibouti, Equatorial Guinea and Chad did not perform to expectation, possibly due to inadequate funding and infrastructural facilities. As to why countries like South Africa, Kenya, Nigeria, Ghana, Uganda, Tanzania, Cameroon, Ethiopia, Malawi, Rwanda and Zambia perform better, the author postulates that this can be due to support from their respective governments and other related institutions like South African Medical Council, United States Agency for International Development, Bill and Melinda Gates Foundation, National Institute of Allergy and Infectious Diseases, National Research Foundation, Well come Trust, National Institute of Mental Health, Foundation for the National Institute of Health and Fogarty International Centre. Therefore, it is imperative to support organisations that advance research and development in every economy.

\section{Conclusion}

The study established that there is no uniformity in the results obtained in the publication on Scopus regarding HIs in Africa. Broad data and knowledge of health and medical practices are significant in the present-day information and knowledge economy. These are used to transform the evolving and growing nature of work in recent times. Although, a paucity of research in HIs, shows that researchers need to strategize on how to have progressive in-depth research practices. The outcome of mapping such publication patterns in a specific field was to analysis how scholars/academic research work contributes to systematic policy and research organisation. This was based on inclusivity in education, where deepened knowledge of researchers/scholars and medical practitioners are shared. It is believed that this study will add value to existing literature in the areas of HIs and strengthen scholarly communication and knowledge sharing in the HIs field. The visibility of research output over these years, 1987 to 2018, could assist academics/scholars and medical practitioners in the development of knowledge management strategies and the optimal use of databases and other institutional repository that house research output in HIs. The publication analysis could be used for appropriate strategic planning and decision making in medical practices based on the numbers of data harvested and required by practitioners on daily basis, to enhance their service delivery. The data and information harvested from different databases could also support local science discovery and institutional growth in Africa, considering the paucity of databases that houses data and information in organisations.

\section{References}

Al-Rowibah, F.A., 2019. Introduction to health informatics. Available at: https://slideplayer.com/slide/8143127/ [Accessed 15 September 2019]

Ammenwerth, E. 2019. Evidence-based health informatics: how do we know what we know? Methods of Information in Medicine, 54(4), pp. 298-307 DOI: 10.3414/ME14-01-0119.

Araújo, E.B., Moreira, A.A., Furtado, V., Pequeno, T.H.C, and Andrade, J.S., 2014. Collaboration networks from a large CV database: dynamics, topology and bonus impact, PLoS One, 9(3), pp. 1-7.

Aziz, H.A, 2015. Health informatics-introduction, Clinical Laboratory Science; 28(4), pp.238-239

Baby, K. and Kumaravel, J.P.S., 2012. Research productivity of Periyar University: a bibliometric analysis, International Research Journal of Library, Information and Archival Studies; 1(1), Available at: www.researchgate.net/publication/230636467_Research_Productivity_of_Periyar_university_A_Bibliometric_Analys is. [Accessed 20 August 2019].

Chuang, K-Y., Chuang, Y-C., Ho, M. and Ho, Y-S., 2011. Bibliometric analysis of public health research in Africa: the overall trend and regional comparisons, South African Journal of Science; 107(5-6), pp. 54-59

Detmar, D.E., 2000. Information technology for quality health care: a summary of UK and US experiences. Quality in Health Care; 9, (3), pp. 181-189

Ebermann, P. 2016. Patents as protection of traditional medical knowledge. Cambridge: Intersentia Publishing

Egghe, L.A., 2010. New short proof of Naranan's theorem, explaining Lotka's law and Zipf's law, Journal of the American Society for Information Science \& Technology, 61(12), pp. 2581-2583.

Glover, S.W. and Bowen, S.L., 2004. Bibliometric analysis of research published in tropical medicine and international health: 1996-2003. Tropical Medicine and International Health, 9(12), pp. 1327-1330.

Greenes, R.A. Shortliffe, E.H., 1990. Medical informatics: an emerging academic discipline and an institutional priority. JAMA: The Journal of the American Medical Association, 263(8), pp. 135-142.

Healthcare Administration Degree Programs, n.d. What is Health Informatics? Available at: https://www.healthcareadministration-degree.net/faq/what-is-health-informatics/ [Accessed 3 September 2019]

Kazemi, A., n.d. Health informatics. https://slideplayer.com/slide/7498727/

Macías-Chapula, C.A. and Mijangos-Nolasco, A., 2002. Bibliometric analysis of AIDS literature in Central Africa. Scientometrics, 54(2), pp 309-317. doi:10.1023/A:1016074230843 
Mapping Africa's natural resources, 2018. An overview of the continent's main natural resources. Doha, Qatar: Aljazeera Media Network, Available at: https://www.aljazeera.com/indepth/interactive/2016/10/mapping-africa-naturalresources-161020075811145.html [Accessed 20 September 2019].

Marais D. L. and Petersen I., 2015. Health system governance to support integrated mental health care in South Africa: challenges and opportunities. International Journal of Mental Health Systems. 9(1), p. 14.

Morris, T.A. and McCain, K.W., 1998. The structure of medical informatics literature. Journal of the American Medical Informatics Association; 5(5): pp. 448-466

Naranan, S., 1971. Power law relations in science bibliography, Journal of Documentation; 27 (2), pp. 83-97.

Nwagwu, W.E., 2006. A bibliometric analysis of productivity patterns of biomedical authors of Nigeria during 1967-2002, Scientometrics, 9 (2), pp. 259-269.

Oleribe, O.O., Momoh, J., Uzochukwu, B.S.C., Mbofana, F., Adebiyi, A., Barbera, T., Williams, R., Taylor-Robinson, S.D., 2019. Identifying key challenges facing healthcare systems in Africa and potential solutions. International Journal of General Medicine, 12 (1), pp. 395-403.

Onyancha, O.B., 2010. Mapping research areas and collaboration in the College of Human Sciences, University of South Africa. Inkanyiso Journal of Humanities and Social Sciences; 2(2), pp. 86-97.

Onyancha, O.B. and Ocholla, D.N., 2009. Is HIV/AIDS in Africa distinct? What can we learn from an analysis of the literature? Scientometrics, 79(2), pp. 277-296.

Owusu-Ansah, F.E. and Mji, G., 2013. African indigenous knowledge and research. African Journal of Disability, $2(1), \mathrm{pp} 30$. Available at: https://doi.org/10.4102/ajod.v2i1.30.

Park, HA. 2016. Are we ready for the Fourth Industrial Revolution? Yearbook Medical

Informatics, 25(1), pp.1-3.

Petersen I, Marais D, Abdulmalik J, Ahuja S, Alem A, Chisholm D, Egbe C, Gureje O, Hanlon C, Lund C, Shidhaye R, Jordans M, Kigozi F, Mugisha J, Upadhaya N, Thornicroft G. 2017. Strengthening mental health system governance in six lowand middle-income countries in Africa and South Asia: challenges, needs and potential strategies. Health Policy Plan; 32(5), pp. 699-709. doi:10.1093/heapol/czx014

Rotich D.C. and Onyancha, O.B., 2016. Trends and patterns of medical and health research at Moi University, Kenya, between 2002 and 2014: an infometrics study, South African Journal of Library \& Information Science, 82(2), pp 2033.

Ruiz-Castillo, J. and Costas, R., 2014. The skewness of scientific productivity, UC3M Working Papers, Departamento de Economía Economics Universidad Carlos III de Madrid 14-02, Calle, Madrid; pp. 1-56.

Saunders, M., Lewis, P. and Thornhill, A., 2009. Research methods for business students (5th rev ed). London: Prentice Hall/Financial Times.

Schorr, A.E., 1974. Lotka's law and library science, Research quarterly, 14(1), pp. 32-33.

Smith, R., 1997. The future of healthcare systems: information technology and consumerism will transform healthcare worldwide. BMJ, 314, pp. 1495-1496

Sodi, T., Mudhovozi, P., Mashamba, T., Radzilani-Makatu, M., Takalani, J., and Mabunda, J., 2011. Indigenous healing practices in Limpopo Province of South Africa: a qualitative study. International Journal of Health Promotion Educ.; 49(3), pp. 101-10.

Suen, H.Y. and Yang, J.M., 2012. Patterns of research productivity in the virtual worlds literature: a bibliometric approach, Scientometrics, 2(2), pp. 77-88.

Sudhier, K.G.P., 2013. Lotka's law and pattern of author productivity in the area of physics research, Journal of Library \& Information Technology; 33(6) pp. 457-464.

Sullivan, F., 2001. What is health informatics? Journal of Health Services Research \& Policy, 6(4), pp. 251-254

Tierney, W.M., 2001. Improving clinical decisions and outcomes with information: a review. International Journal of Medical Informatics; 62(1), pp. 1-9

Torbati, A.S and Chakoli, A.N., 2013. Empirical examination of Lotka's law for applied mathematics, Life Science Journal, 10(5), pp. 601-607.

Turner, A., Kushniruk, A. and Nohr, C., 2017. Are we there yet? Human factors Knowledge and Health Information Technology - the challenges of implementation and impact, Yearbook Medical Informatics, 26(1), pp. 84-91; Available at: https://www.ncbi.nlm.nih.gov/pmc/articles/PMC6239238/pdf/10-15265-IY-2017-014.pdf [Accessed October 20 2019]

WHO, 2007. Everybody's business: strengthening health systems to improve health outcomes. WHO's Framework for Action. Geneva: World Health Organization 